\begin{tabular}{|c|l|}
\hline Title & Measurement of surface dryout near heating surface at high heat fluxes in subcooled pool boiling \\
\hline Author(s) & Ono, Ayako; Sakashita, Hiroto \\
\hline Citation & $\begin{array}{l}\text { International Journal of Heat and Mass Transfer, 52(3-4), 814.821 } \\
\text { https://doi.org/40.1016/.ijheatmasstransfer.2008.07.042 }\end{array}$ \\
\hline Issue Date & 2009-01-31 \\
\hline Doc URL & http://hdl.handle.net/2115/42769 \\
\hline Type & article(author version) \\
\hline File Information & IJHMT52-3-4_814-821.pdf \\
\hline
\end{tabular}

Instructions for use 


\section{Measurement of Surface Dryout near Heating Surface at High Heat Fluxes in Subcooled Pool Boiling}

Ayako Ono a and Hiroto Sakashita ${ }^{a}, *$

a Division of Energy and Environmental Systems, Graduate School of Engineering,

Hokkaido University, North 13 West 8, Kita-ku, Sapporo 060-8628, Japan

* Corresponding author. Tel.: +81 11706 6664, Fax.: +81 117066664

E-mail address: saka@eng.hokudai.ac.jp 


\section{Abstract}

The authors have conducted measurements of liquid-vapor behavior in the vicinity of a heating surface for saturated and subcooled pool boiling on an upward-facing copper surface by using a conductance probe method. A previous paper [A. Ono, H. Sakashita, Liquid-vapor structure near heating surface at high heat flux in subcooled pool boiling, Int. J. Heat and Mass Transfer, 50(2007), 3481-3489] reported that thicknesses of a liquid rich layer (a so-called macrolayer) forming in subcooled boiling are comparable to or thicker than those formed near the critical heat flux $(\mathrm{CHF})$ in saturated boiling. This paper examines the dryout behavior of the heating surface by utilizing the feature that a thin conductance probe placed very close to the heating surface can detect the formation and dryout of the macrolayer. It was found that the dryout of the macrolayer formed beneath a vapor mass occurs in the latter half of the hovering period of the vapor mass. Two-dimensional measurements conducted at 121 grid points in a $1 \mathrm{~mm} \times 1 \mathrm{~mm}$ area at the center of the heating surface showed that the dryout commences at specific areas and spreads over the heating surface as the heat flux approaches the CHF. Furthermore, transient measurements of wall void fractions from nucleate boiling to transition boiling were conducted under the transient heating mode, showing that the wall void fraction has small values $(<10 \%)$ in the nucleate boiling region, and then steeply increases in the transition boiling region. These findings strongly suggest that the macrolayer dryout model is the most appropriate model of the CHF for saturated and subcooled pool boiling of water on upward facing copper surfaces.

Key Words: Pool boiling, Critical heat flux, Macrolayer, Dryout, Subcooled boiling, Conductance probe 


\section{Introduction}

Various models of CHF mechanisms in saturated pool boiling have been proposed. Zuber [1] postulated that vapor escapes from a heating surface as large vapor jets and proposed a hydrodynamic instability model in which the Helmholtz instability at the interface between the vapor jets and the surrounding liquid causes the CHF. This model is also termed the 'far field model' because it assumes that liquid-vapor behaviors far from the heating surface trigger the CHF. Katto and Yokoya [2] proposed the macrolayer dryout model in which the CHF occurs when a liquid layer (a so-called macrolayer) formed beneath a large vapor mass dries out just before the departure of the vapor mass. This model is termed the 'near field model' because the liquid-vapor behaviors near the heating surface are related to the $\mathrm{CHF}$ trigger. The existence of a liquid-layer beneath the vapor masses has been confirmed by Iida and Kobayasi [3], Bhat et al. [4], Rajivanshi et al. [5], Shoji [6], and Ono and Sakashita [7] by using conductance probes, and by Auracher and Marquard [8] by using an optical probe. Unal et al. [9] proposed a model in which the CHF is reached when a dry area on a heating surface reaches a temperature at which the liquid can no longer maintain contact. This model is also termed the 'on surface model' because it assumes the liquid-vapor behaviors on the boiling surface are related to the trigger of CHF. Theofanous [10] boiled water on a glass plate coated with titanium of a few 100 to $1000 \mathrm{~nm}$ in thickness and measured thermal patterns on the plate by using an infrared radiation thermometer. Through this measurement, they confirmed that dry spots formed within primary bubble bases serve as precursors of the CHF. This result suggests that the model by Unal et al. [9] may be applied to a heating surface with small heat capacity such as thin metal films used in the experiments of Theofanous et al. or thin wires. Auracher and Marquardt [8] analytically examined the stability 
limit of a dry spot formed on a copper surface in water boiling at a heat flux of $0.9 \mathrm{MW} / \mathrm{m}^{2}$. They reported that in the case of a $0.1 \mathrm{~mm}$ thick copper heater a dry spot of some tenths of a mm becomes unstable and expands on the heating surface to trigger the CHF. For a $10 \mathrm{~mm}$ thick copper heater a dry spot of more than $8 \mathrm{~mm}$ is required to trigger the CHF. The above models are based on different trigger mechanisms, and some kind of change should appear in the liquid-vapor behavior close to the heating surface before and after the CHF.

Further, there are other models which consider that the boiling behavior shifts smoothly from nucleate boiling through the CHF to transition boiling and the CHF should be determined from a competition between the heat transfer enhancement with increasing wall superheat and the deterioration in heat transfer by the expansion of the dry areas on the heating surface. As this type of model, Dhir and Liaw [11] proposed a time and area averaged model that assumes stationary vapor stems penetrating a thin thermal layer adjacent to a heating surface. This model explains the boiling curve from the fully developed nucleate boiling to the film boiling by considering changes in the wall void fraction. Nishio et al. [12,13] boiled R113 and R141b on a single crystal sapphire and observed the bubble behavior through the sapphire from below. They observed that at high heat flux in the nucleate boiling region the bases of the primary and coalesced bubbles almost dry out and that a wetted area exists only as a network of irregular continuous canals of liquid. Based on these observations Nishio et al. [12,13] defined contact-line length density (CLLD) and proposed a CHF model [13] in which the CHF point corresponds to the condition where the CLLD reaches a maximum value and the condition is satisfied when the primary bubbles fully cover the heating surface.

All models mentioned above were derived for the CHF at saturated boiling. 
In subcooled boiling, however, it is widely known that the CHF increases remarkably with increasing subcooling. Figure 1 shows the variation in $\mathrm{CHF}$ with subcooling measured on copper horizontal upward-facing surfaces smaller than 10 $\mathrm{mm}$ in diameter in water boiling $[7,14-16]$. In the ranges of subcooling and the size of the heating surface of Fig.1, the boiling behavior in nucleate boiling near the $\mathrm{CHF}$ is similar to that in saturated boiling; large vapor masses completely cover the heating surface and detach or collapse periodically on the heating surface. These similarities in boiling phenomena near the CHF suggest that the mechanisms of the CHF are also similar for saturated and subcooled boiling. It may therefore be expected that a physically appropriate model for saturated boiling is able to explain the $\mathrm{CHF}$ in subcooled boiling as well. To clarify the $\mathrm{CHF}$ mechanism for saturated and subcooled boiling, the authors [7] measured liquid-vapor behavior near the heating surface using conductance probes and showed that there is a liquid macrolayer between the surface and vapor mass even at very high heat fluxes in subcooled boiling above the CHF in saturated boiling. They specified the thickness of the macrolayer from location of disappearance of vapor mass signals and found that the liquid macrolayer formed at high heat fluxes in subcooled boiling is as thick as those formed near the CHF in saturated boiling.

The objective of this study is to determine the trigger mechanism of the CHF in saturated and subcooled boiling based on detailed measurements of dryout behaviors of liquid macrolayers by using a conductance probe placed very close to the heating surface.

\section{Experiment}

The experiments were conducted using water at atmospheric pressure over a 
range of subcooling from $0 \mathrm{~K}$ to $40 \mathrm{~K}$. Figure 2 shows the experimental apparatus. The details of the experimental apparatus were reported in a previous paper [7]. The top surface of a conical copper block served as the horizontal upward facing 8 mm diameter heating surface. The heating surface was finished with \#1000 emery paper before each experiment. Three thermocouples of $0.5 \mathrm{~mm}$ diameter were embedded in the copper block 5,13 , and $21 \mathrm{~mm}$ below the heating surface. The surface temperature and heat flux were calculated with the three thermocouples by considering the conical copper block as a part of a hollow sphere. The subcooling was defined by the liquid temperature measured at the same height as the heating surface, $20 \mathrm{~mm}$ from the center of the surface.

The measurement system with a conductance probe is described in detail in [7]. The tip of the conductance probe was thinned to less than $5 \mu \mathrm{m}$ by an electro-polish technique. An AC voltage of $24 \mathrm{kHz}$, resonance frequency of the measurement circuit, was applied between the conductance probe and the heating surface. The conductance probe was connected to a three-dimensional moving stage with an accuracy of $0.5 \mu \mathrm{m}$ in the perpendicular direction and $10 \mu \mathrm{m}$ in the horizontal direction (the moving probe in the following, A-probe in Fig.2). A further probe was used to selectively measure the behaviors of vapor masses (the fixed probe in the following, B-probe in Fig.2). The fixed probe was placed near the center of the heating surface $4 \mathrm{~mm}$ over the surface. The probe signals were stored in a $\mathrm{PC}$ through the $\mathrm{A} / \mathrm{D}$ converters with a time resolution of $10 \mu \mathrm{s}$, much shorter than the time resolution of $42 \mu$ s determined from the resonance frequency of the electrical circuit. During the measurements, potassium chloride was added to increase the electro conductivity of the water.

\section{Results and Discussion}




\subsection{Static characteristics of the conductance probe}

Figure 3 shows the characteristics of the output voltage from the moving probe when the probe was pushed down from the atmosphere into the water (or pushed up from the water into the atmosphere) under the condition that the water and the heating surface were not heated and the water level was set several millimeters above the heating surface. As the absolute values of the voltage change depending on an applied voltage between the probe and the heating surface, the right vertical axis in Fig.3 shows relative values normalized by the maximum output voltage. The zero mm of distance corresponds to a location where the prove tip contacts the water surface. The voltage falls instantaneously to about half the maximum voltage at the moment of the probe tip-water contact, then decreases gradually as the probe tip penetrates deeper below the surface of the water, and reaches an almost a constant low value when the probe tip is below a depth of around $0.4 \mathrm{~mm}$. This result comes from the feature that in the conductance probe the sensitivity of the probe tip is quite high. As a consequence, the probe outputs the intermediate value between high and low voltages (about $55 \%$ of the maximum voltage in Fig.3) just when the probe tip comes in contact with the liquid. The correspondence between these static characteristics and the probe signals obtained in the boiling experiment will be explained in the next section. In Fig.3, no distinct hysteresis was observed for the output voltages obtained when lowering and raising the probe around the water surface. Therefore, it is concluded that any effect of liquid adhesion on the probe tip due to surface tension is weak.

\subsection{The detection of surface dryout by conductance probe}

Figure 4 shows the probe signals obtained at high heat flux ( $81 \%$ of the CHF. 
Fig.4-(a)) and near the CHF (97\% of the CHF. Fig.4-(b)) in the nucleate boiling region at $20 \mathrm{~K}$ subcooling. In each figure, the top signals are obtained from the moving probe positioned at a height of 1 or $5 \mu \mathrm{m}$, and the bottom signals from the fixed probe, representing the behavior of the vapor masses. In Fig.4-(a), the signals from the moving probe positioned near the heating surface are of low voltage, indicating the existence of a liquid layer beneath the vapor masses. In Fig.4-(b) very close to the CHF, the signals from the moving probe reach higher voltages in the latter half of the vapor mass hovering.

Figure 5 represents Fig.4-(b) signals of the moving and fixed probes during one hovering cycle of the vapor mass. The moving probe signals are divided into three regions (A, B, and $\mathrm{C}$ ) according to the magnitude of the output voltage. From the correspondence with the static characteristics shown in Fig.3, it appears that region A (low voltage region) corresponds to a situation where the whole of the probe is covered with liquid, region B (intermediate voltage region) is where the tip of the probe is in contact with liquid and the remaining part of the probe is covered with vapor, and region $\mathrm{C}$ (high voltage region) is where the whole of the probe is covered with vapor. With the experimental results that the signals accompanying region $\mathrm{C}$ appear only near the $\mathrm{CHF}$, it may be suggested that the signals of Fig.5 indicate the occurrence of surface dryout at the probe location. It is, therefore, considered that a duration of region A indicates a waiting time during the formation the large vapor mass, the duration of region $\mathrm{B}$ indicates the lifetime of the liquid layer under the large vapor mass, and the duration of region C indicates a period of surface dryout. According to this interpretation, the total duration of regions $\mathrm{B}$ and $\mathrm{C}$ should correspond to the hovering period of the large vapor mass. To verify this, the durations of $\mathrm{B}+\mathrm{C}$ (or the durations of region $\mathrm{B}$ when the dryout signals were not detected) were compared with the data for the 
vapor mass hovering periods reported in [7]. The hovering periods were in good agreement with each other. Therefore, Figs.4-(b) and 5 indicate that the heating surface dried out in the latter half of the vapor mass hovering period. However, Fig.4-(b) with probe signals for $0.2 \mathrm{~s}$ during which only three dryout events appeared, is not sufficient to draw the conclusion that the surface dryout always occurs in the latter half of the vapor mass hovering period.

Therefore, to specify when in the vapor mass hovering period dryout is likely to occur, variations in the void fraction due to the surface dryout during the vapor mass hovering period were estimated in the following manner. In Fig.4-(b), the vapor mass signals detected by the fixed probe positioned at $4 \mathrm{~mm}$ height and by the moving probe at $5 \mu \mathrm{m}$ height are nearly synchronous, but there is some time-lag due to the differences in the heights of the two probes. To avoid errors due to this time-lag, the vapor mass hovering periods were also determined from the moving probe signals.

The signals from the moving probe were bifurcated into two identical signals, and the respective signals were digitized with different threshold voltages: one at the intermediate between the voltages of regions $\mathrm{A}$ and $\mathrm{B}$, and the other that between regions B and C. In Fig.5, the two threshold voltages are indicated as $V_{\text {th1 }}$ and $V_{\text {th2 }}$, and the binary signals digitized with these two voltages are shown below the probe signals. The pulse width digitized with $\mathrm{V}_{\text {th1 }}$ corresponds to the dryout period and the pulse width digitized with $\mathrm{V}_{\text {th2 }}$ is the vapor mass hovering period. (In this paper, a high digitized binary signal is termed a pulse and its width as the pulse width.) The measurements were conducted over 20s near the CHF for $30 \mathrm{~K}$ subcooling, and all the pulses of the vapor mass accompanying the occurrence of the dryout were selected. Then, each pulse (hovering period of the each vapor mass) was divided evenly into ten, and 
time fraction of the dryout in each of the ten periods was calculated. The time fraction of the dryout in each time width averaged over 20s is plotted in Fig.6. The horizontal axis is the non-dimensional time normalized by the vapor mass hovering period. For all cases with the three different heat fluxes, the dryout rarely appears in the first half of the hovering period and almost always occurs in the latter half of the hovering period. In Fig.6, the dryout time fractions sharply decrease in the last part of the hovering period. This is probably because the tip of the probe contacts first with liquid flowing onto the drying surface while the vapor mass is detaching, and consequently that the probe is temporarily put under the same situation as that of region B.

From the results above, it is concluded that the signals of the moving probe shown in Fig.4-(b) indicates a sequential process: the detachment of the preceding vapor mass, the inflow of bulk liquid, the formation of vapor mass and macrolayer beneath it, and surface dryout by consumption of the macrolayer.

Figure 7 shows previously reported data of the macrolayer thickness [7] determined from the location at which the signals of the vapor mass disappear. The lowest heat flux in each subcooling condition, except for the saturated condition, is the heat flux at which the large vapor mass covering the whole area of the heating surface begins to form - the lowest heat flux of the vapor mass region. In this figure, the open symbols indicate that surface dryout was detected. In each subcooling condition, the macrolayer thickness decreases with the increase in the heat flux and dries out when the heat flux approaches the CHF.

\subsection{The 2-D measurements of surface dryout}

To examine the two-dimensinal dryout behaviors on the heating surface, measurements were conducted at 121 grid points arranged at $0.1 \mathrm{~mm}$ intervals in 
a $1 \mathrm{~mm} \times 1 \mathrm{~mm}$ region at the center of the heating surface. The probe traversed horizontally at a height of 3 to $5 \mu \mathrm{m}$ from the heating surface and the fractions of dryout time to the measurement time (termed 'dryout void fraction') were obtained at the 121 measuring points. Figure 8 shows the 2-D distributions of the dryout void fractions obtained at two different heat fluxes near the $\mathrm{CHF}$ for $20 \mathrm{~K}$ subcooling. In Fig.8-(a) with the heat flux $\mathrm{q}=2.97 \mathrm{MW} / \mathrm{m}^{2}(94 \%$ of the $\mathrm{CHF})$ at which the dryout begins to appear, here the dryout is limited to some areas and the dryout void fractions are small with values of less than 1.5\%. In Fig.8-(b) where the heat flux is slightly higher at $\mathrm{q}=3.01 \mathrm{MW} / \mathrm{m}^{2}(95 \%$ of the $\mathrm{CHF})$, the dryout areas enlarge greatly and the dryout void fractions also increase to a maximum of about $21 \%$. Based on these $2-\mathrm{D}$ dryout void fractions, area-averaged dryout void fractions were calculated and are shown in Fig.9. The area averaged dryout void fraction increases steeply in the very narrow heat flux range from the condition where dryout is initiated to the CHF. However, the area averaged dryout void fraction at the $\mathrm{CHF}$ remains small, 5 to $15 \%$.

\subsection{Relation of dryout onset locations with nucleation sites}

The distribution of the dryout void fraction in Fig. 8 shows that the dryout of the macrolayer commences at a specific area on the heating surface and is followed by a rapid enlargement of the dried out area. To determine the trigger leading to local dryout of the macrolayer, the relation between dryout onset locations and nucleation sites was evaluated in the following manner.

When the moving probe travels in the horizontal direction at high heat fluxes near the $\mathrm{CHF}$, the probe is often at specific locations where signals of surface dryout as shown in Fig.4 and also signals corresponding to primary bubble generation as shown in Fig.10 are concurrently detected. The spectrum of the 
pulse width of the signals obtained at such location is shown with open circles in Fig.11. Also, the open triangles are the pulse spectrum obtained at a location where the probe detects only the signals of the primary bubble generation. When the probe detects the signals of surface dryout and primary bubble generation concurrently, the corresponding pulse spectrum has a distinct peak in a wider pulse width region. It is, therefore, possible to differentiate signals of dryout and signals of primary bubbles based on the differences in pulse widths. From the results of Fig.11, pulses narrower than 2ms were regarded as primary bubble signals and pulses wider than $3 \mathrm{~ms}$ as dryout signals. As with the measurement shown in Fig.8, the probe signals were obtained at 121 grid points in a $1 \mathrm{~mm} \times$ $1 \mathrm{~mm}$ region at the center of the heating surface, and classified into dryout signals and primary bubble signals based on the pulse width. The 2-D distributions of dryout frequency and the frequency of generation of primary bubbles are depicted in Fig. 12-(a) and (b), respectively. The highlight regions correspond to dryout locations and nucleation sites. Comparing these two distributions show that the dryout tends to occur near the nucleation sites.

To quantitatively evaluate the relations between dryout locations and nucleation sites, a correlation coefficient $\gamma$ between the dryout frequency and the frequency of generation of primary bubbles was calculated with the following equation.

$$
\gamma=\frac{\sum_{i=1}^{N}\left(f_{n, i}-\bar{f}_{n}\right)\left(f_{d, i}-\bar{f}_{d}\right)}{\sigma_{n} \sigma_{d}}
$$

where $\mathrm{N}$ is the number of the measurement points, $\mathrm{f}_{\mathrm{n}, \mathrm{i}}$ and $\mathrm{f}_{\mathrm{d}, \mathrm{i}}$ are the relative frequencies of primary bubbles and dryout at a point i normalized with each maximum frequency, and $\sigma_{\mathrm{n}}$ and $\sigma_{\mathrm{d}}$ are standard deviations of $\mathrm{f}_{\mathrm{n}, \mathrm{i}}$ and $\mathrm{f}_{\mathrm{d}, \mathrm{i}}$, 
respectively. Changes in the correlation coefficients with heat flux for each subcooling condition are depicted in Fig.13. In general, a value of $\gamma$ between 0 to 0.2 may be interpreted as having none or little correlation, a value between 0.2 and 0.4 a weak correlation, a value between 0.4 and 0.7 a moderate correlation, and a value of $\gamma$ between 0.7 and 1.0 may be seen as having a strong correlation. According to Fig.13, the correlation coefficients at the heat flux where the dryout is initiated take values of 0.4-0.9 (indicating moderate to strong correlations), then decrease rapidly to a region of little or no correlation with the slight increase in heat fluxes for the subcooling conditions. This behavior of the correlation coefficients suggests that the dryout occurs locally around nucleation sites, and then spreads over the heating surface.

\subsection{The trigger mechanism of $\mathrm{CHF}$}

The foregoing sections showed that the dryout occurs in the latter half of the vapor mass hovering period, it commences in a specified area of the heating surface before the $\mathrm{CHF}$ and spreads over the heating surface as the heat flux approaches the CHF. These findings strongly suggest that the dryout of the liquid macrolayer formed on the heating surface is the trigger of the CHF. To verify this deduced trigger mechanism, transient behaviors of liquid/vapor signals close to the heating surface from the nucleate boiling region through the $\mathrm{CHF}$ to the transition boiling region were measured under transient heating modes, realized by stepwise increases in heat input to the copper block initially kept at steady-state conditions at high heat fluxes in nucleate boiling. Figures 14-(a) to (c) show the signals of the moving probe positioned at $10 \mu \mathrm{m}$ together with the changes in the surface superheat. The surface superheat in Fig.14 and the surface heat flux in Fig. 15 are values calculated from the readings of the three 
thermocouples embedded in the copper block. The time delay in the response of the thermocouple at the position nearest to the heating surface $(5 \mathrm{~mm}$ below the surface) to the change in surface temperature is estimated at about 20 to $70 \mathrm{~ms}$. Therefore, the temperature responses may include a time delay during which one to three vapor masses detach, but no corrections were made for calculating the surface temperature and the surface heat flux. Fig.14-(a) shows the behaviors of the surface superheat and the probe signals from 40 to 80 seconds after the measurements started. The sudden increase in the surface superheat commences at 73s, showing the occurrence of the CHF. At this time, the probe signals change suddenly from the fine signals corresponding to the primary bubbles to the surface dryout signals. Figure 14-(b), which has enlarged the temporal axis around the time of the $\mathrm{CHF}$ occurrence, shows that the surface dryout begins to become frequent from 73.0s, almost the time of the CHF. Fig.14-(c) is the enlargement of the point where the dryout signal appeared first, similar to that shown in Fig.4-(b) or Fig.5.

The void fractions obtained by averaging the continuous probe signals of Fig.14 for every one second are shown in Fig.15 together with the corresponding boiling curve. For each subcooling, the void fractions increase rapidly in the transition boiling region. Further, for the case of high subcooling of 30K, it was observed that the void fraction decreases sharply and the heat flux tends to increase again with increasing surface superheat in the transition boiling region (the same trend was observed for the $40 \mathrm{~K}$ subcooling, but due to space limitations data are not shown). These changes in the void fraction and the heat flux appearing at high subcooling can be attributed to the occurrence of MEB (Micro-bubble Emission Boiling), but this paper does not discuss this further as MEB phenomena are outside the scope of the paper. 
In Fig.16, the void fractions for each subcooling condition shown in Fig.15 is re-plotted against the reduced heat flux-ratio of the heat flux to the CHF. To avoid complicating the graph, Fig.16 eliminates the data in the MEB region for $30 \mathrm{~K}$ and $40 \mathrm{~K}$ subcooling. The data for all the subcooling conditions are well correlated and show similar tendencies, the void fraction takes low values of about 10\% before the CHF and increases sharply just after the CHF. Figure 16 also plots the data by Dhuga and Winterton [17] and Nishio and Tanaka [18], who measured boiling curves together with void fractions from nucleate boiling to transition boiling. Dhuga et al. boiled water and methanol on a $28 \mathrm{~mm}$ diameter aluminum heating surface coated with a thin $\mathrm{Al}_{2} \mathrm{O}_{3}$ layer and measured an area averaged void fraction from the variation of impedance between the heating surface and an electrode placed above the surface. Nishio et al. boiled R113, R141b, and ethanol on a single crystal sapphire and measured an area averaged void fraction by observing the dry area from below the surface. The void fractions of water and methanol by Dhuga et al. show similar tendencies to the present data-the void fraction takes small values in the nucleate boiling region and then increases steeply in the transition boiling region. The discrepancies between the present data and the data by Dhuga et al. in the transition boiling region may be because the void fraction in Dhuga et al. is the value averaged over the whole area of the heating surface and therefore includes the liquid contact with the periphery of the surface. In addition, the differences in the area averaged void fraction of Dhuga et al. and the time averaged void fractions of the present data, and difference of the wettability of the heating surface may also be behind the discrepancies. The data by Nishio et al. show that for each liquid the surface dryout appears at very low heat fluxes in the nucleate boiling region and that the area expands to $60-90 \%$ of the heating surface at the CHF. The reason for the inconsistency between the data 
by Nishio et al. and the present data and/or the data by Dhuga et.al are not clear. Differences in the surface conditions, wettability, and roughness of the heating surfaces may play a role.

The all experimental results shown in this section strongly support the following trigger mechanism of the $\mathrm{CHF}$ : the liquid macrolayer formed on the surface is consumed during the vapor mass hovering and as a consequence the dry area spreads rapidly over the heating surface, leading to CHF. Therefore, at least to the CHF for saturated and subcooled pool boiling of water on a copper heating surface with large heat capacity, the macrolayer dryout model would be the most appropriate $\mathrm{CHF}$ model, and the causes of the $\mathrm{CHF}$ increase with increasing subcooling are that a thick macrolayer is able to form in subcooled boiling as shown in Fig. 7 and that the lowest heat flux of the vapor mass region shifts towards the higher heat flux.

\section{Conclusions}

To clarify the CHF mechanism for saturated and subcooled pool boiling, the behavior of surface dryout near the $\mathrm{CHF}$ for water boiling on an upward copper surface was measured using the conductance probe method. The results obtained in the present research may be summarized as follows:

(1) Surface dryout occurs in the latter half of the vapor mass hovering period.

(2) Surface dryout occurs locally at a high heat flux region close to the CHF and spreads rapidly over the surface with slight increases in the heat flux. The dryout void fraction averaged over the heating surface, however, remains small, about 5 to $15 \%$, even at $\mathrm{CHF}$.

(3) Under the transient heating mode, the signals from the fixed probe placed close to the heating surface change suddenly from the signal of the primary 
bubbles to the signal of surface dryout when the boiling mode changes from nucleate boiling to transition boiling. At the $\mathrm{CHF}$, the dryout signal appears at the latter half of the vapor mass hovering period.

(4) From conclusions (1)-(3), the CHF mechanism of saturated and subcooled pool boiling under the present boiling conditions-water boiling on an upward copper surface with large heat capacity - is very close to the macrolayer dryout model.

(5) Therefore, the CHF increases with increasing subcooling because a thick macrolayer is able to form in subcooled boiling and as the lowest heat flux of the vapor mass region shifts towards the higher heat flux. 


\section{REFERENCES}

[1] Zuber, N., On the stability of boiling heat transfer, American Society of Mechanical Engineers Journal of Heat Transfer, Vol.80 (1958), pp.711-720.

[2] Katto, Y. and Yokoya, S., Principal mechanism of boiling crisis in pool boiling, International Journal of Heat and Mass Transfer, Vol.11 (1968), pp.993-996.

[3] Iida, Y. and Kobayasi, K., An experimental investigation on the mechanism of pool boiling phenomena by a probe method, Proceedings of the $4^{\text {th }}$ International Heat Transfer Conference, Paris, 5 (1970), pp.1-11.

[4] Bhat, A. M. et al., Role of macrolayer evaporation in pool boiling at high heat flux, International Journal of Heat and Mass Transfer, Vol.11 (1986), pp.953-1961. [5] Rajvanshi, A. K. et al., Investigation of macrolayer thickness in nucleate pool boiling, International Journal of Heat and Mass Transfer, Vol.35 (1992), pp.343-350.

[6] Shoji, M., A study of steady transition boiling of water: experimental verification of macrolayer evaporation model, Pool and External Flow Boling, Dhir, V. K. et al. ed., American Society of Mechanical Engineers (1992), pp.237-242. [7] Ono, A and Sakashita, H., Liquid-vapor structure near heating surface at high heat flux in subcooled pool boiling, International Journal of Heat and Mass Transfer, Vol.50 (2007), pp.3481-3489.

[8] Auracher, H. and Marquardt, W., Heat transfer characteristics and mechanisms along entire boiling curves under steady-state and transient conditions, International Journal of Heat and Fluid Flow, Vol.25 (2004), pp.223-242.

[9] Unal, C. et al., Unifying the controlling mechanisms for the critical heat flux and quenching, Transactions of the American Society of Mechanical Engineerings, Journal of Heat Transfer, Vol.114 (1992), pp.972-982. 
[10] Theofanous, T. G. et al., The boiling crisis phenomenon Part2: dryout dynamics and burnout, Experimental Thermal and Fluid Science, Vol.26 (2002), pp.793-810.

[11] Dhir, V. K. and Liaw, S. P., Framework for a unified model for nucleate and transition pool boiling, Transactions of the American Society of Mechanical Engineers, Journal of Heat Transfer, Vol.111 (1987), pp.739-746.

[12] Nishio, S., Gotoh, T. and Nagai, N., Observation of boiling structures in high heat-flux boiling, International Journal of Heat and Mass Transfer, Vol.41 (1998), pp.3191-3201.

[13] Nishio, S. and Tanaka, H., Simplified model predicting contact-line-length density at criticalheat flux based on direct observation of boiling structure, Japan Society of Mechanical Engineers International Journal, Series B, Vol.45 (2002), pp.72-78.

[14] Li, J. et al, Study of critical heat flux in subcooled pool boiling (in Japanese), Proceedings of $36^{\text {th }}$ National Heat Transfer Symposium of Japan (1999), pp.391-392.

[15] Yokoya, S. et al., Critical heat flux in high subcooled pool boiling (in Japanese), Proceedings of 37th National Heat Transfer Symposium of Japan (2000), pp.65-66.

[16] Inada, S. et al., Studies on boiling curves in subcooled pool boiling: $4^{\text {th }}$, Heat transfer mechanism in transition boiling region (in Japanese), Transaction of the Japan Society of Mechanism Engineers, Series B, Vol.47, No.423 (1981), pp.2199-2208.

[17] Dhuga, D. S. and Winterton, R. H. S., Measurements of surface contact in transition boiling, International of Journal Heat and Mass Transfer, Vol.28, No.10 (1985), pp.1869-1880. 
[18] Nishio, S. and Tanaka, H., Visualization of boiling structures in high heat-flux pool-boiling, International Journal of Heat and Mass Transfer, Vol.47 (2004), pp.4559-4568 


\section{Captions of figures}

Figure 1 Variation in CHF with subcooling.

Figure 2 Experimental apparatus.

Figure 3 Static characteristics of conductance probe signals.

Figure 4 Probe signals near the heating surface in the nucleate boiling region and near CHF.

Figure 5 Three characteristic regions of probe signal detecting surface dryout.

Figure 6 Dryout time fractions during vapor mass hovering.

Figure 7 Liquid macrolayer thickness (open symbols indicate surface dryout).

Figure $8 \quad 2$-D distribution of dryout void fractions.

Figure 9 Area-averaged dryout void fractions.

Figure 10 Probe signals of primary bubbles.

Figure 11 Spectra of pulse widths.

Figure 12 Dryout frequency (a) and nucleation frequency (b). $\left(\Delta \mathrm{T}_{\text {sub }}=20 \mathrm{~K}, \mathrm{q}=2.97 \mathrm{MW} / \mathrm{m}^{2}\right)$

Figure 13 Correlation coefficient between dryout frequency and nucleation frequency. (arrows indicate the heat flux of onset of dryout ).

Figure 14 Change in probe signals before and after CHF.

Figure 15 Simultaneously measured boiling curves and wall void fractions.

Figure 16 Present and previously reported wall void fractions. 


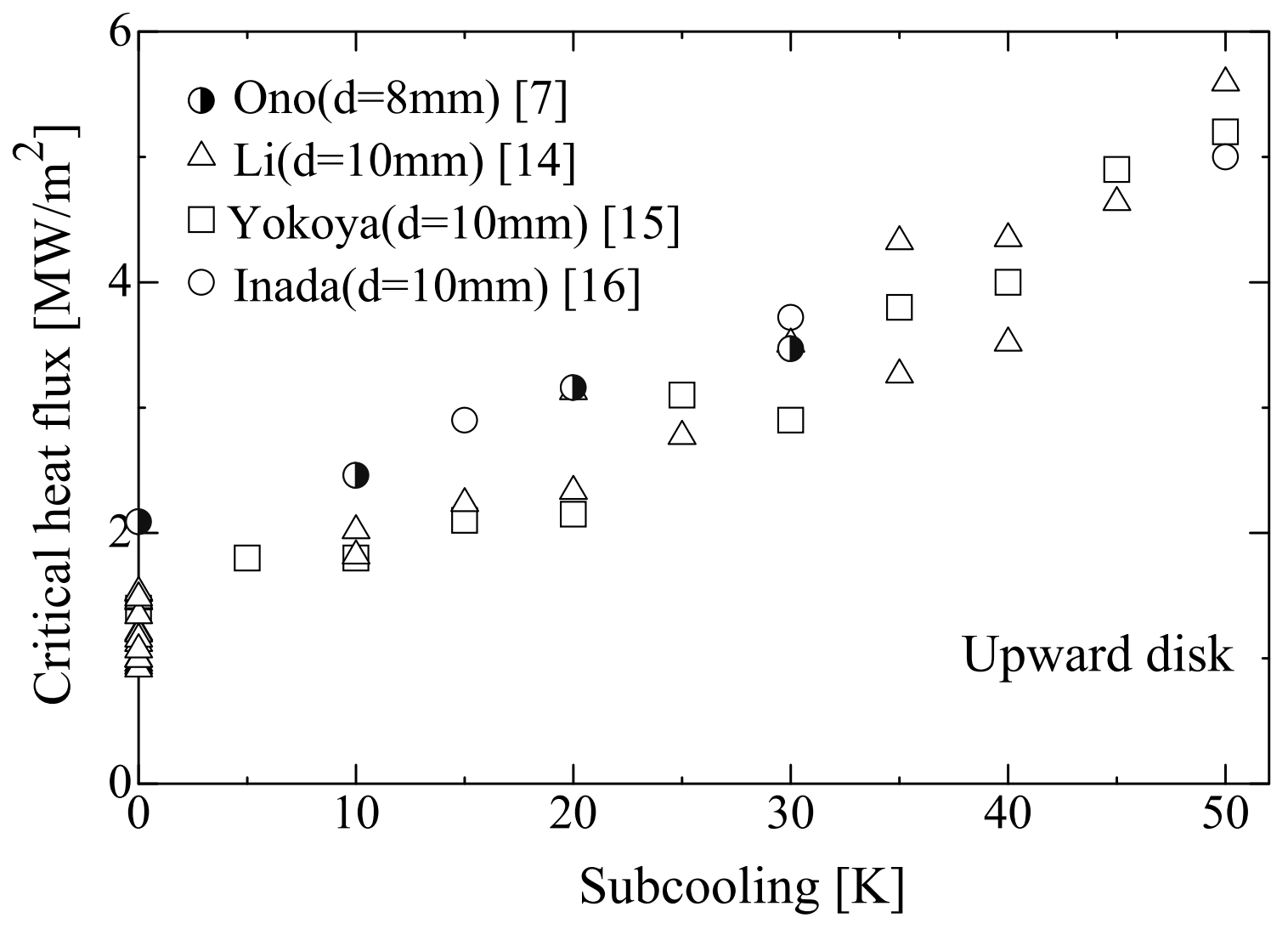

Figure 1 Variation in CHF with subcooling. 


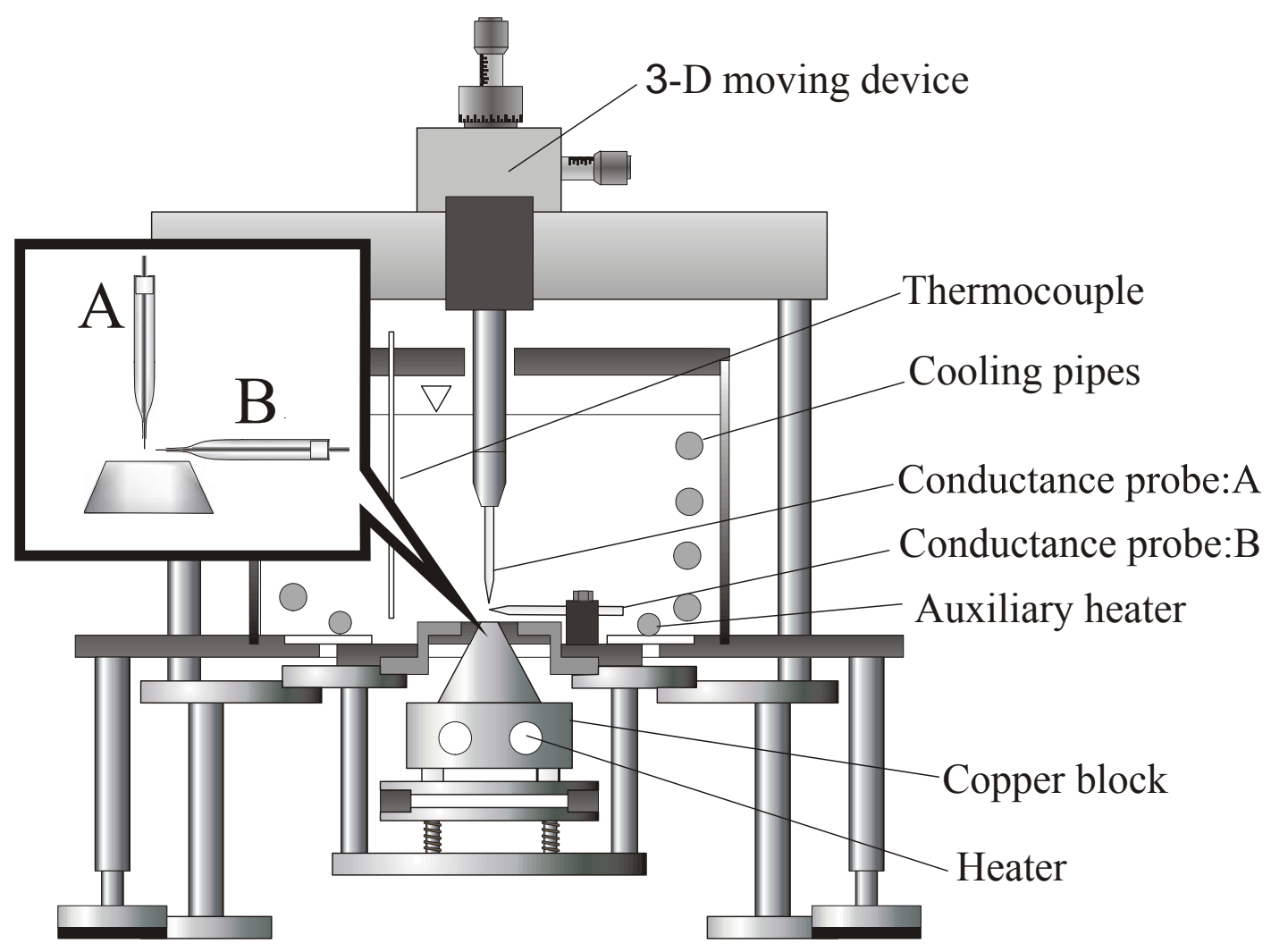

Figure 2 Experimental apparatus 


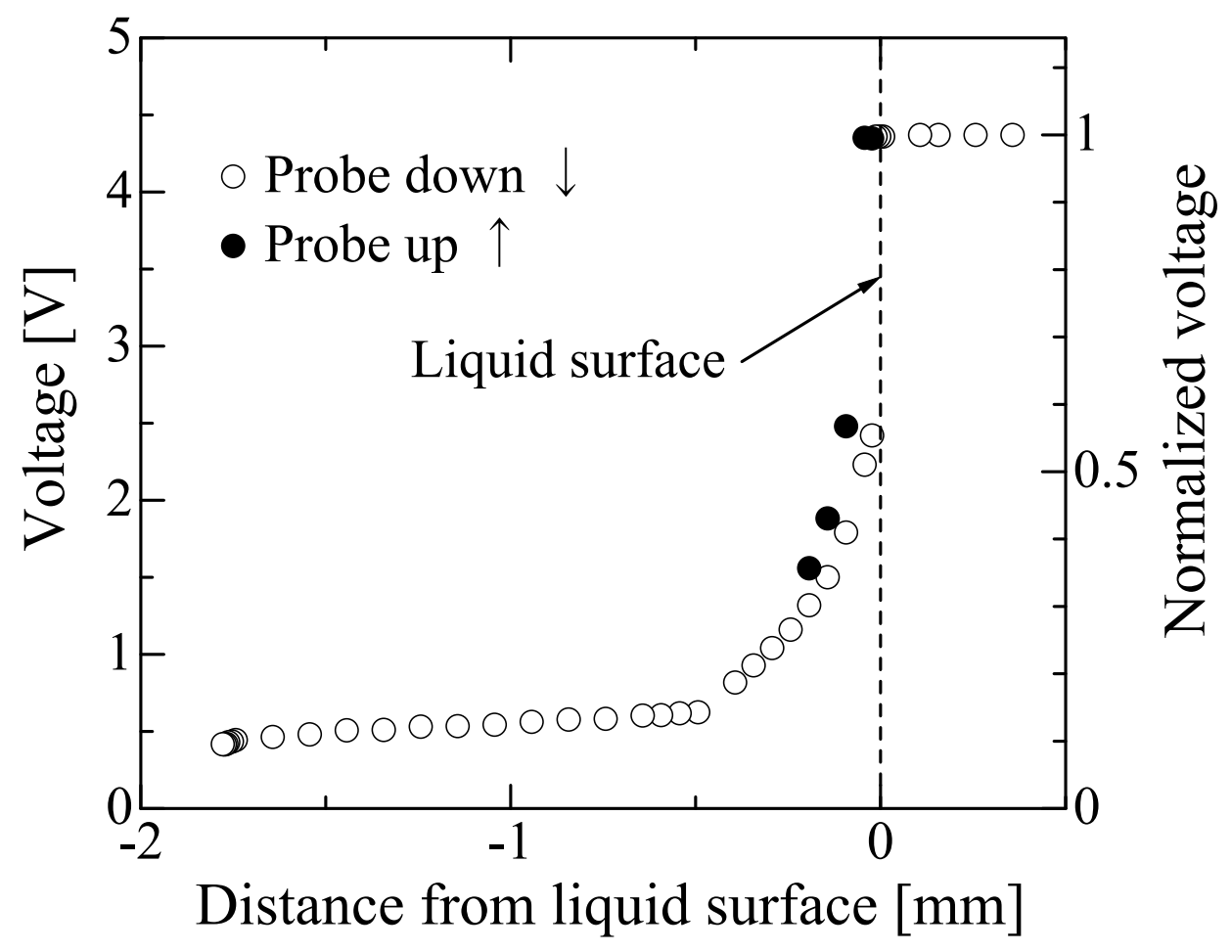

Figure 3 Static characteristics of conductance probe signals. 

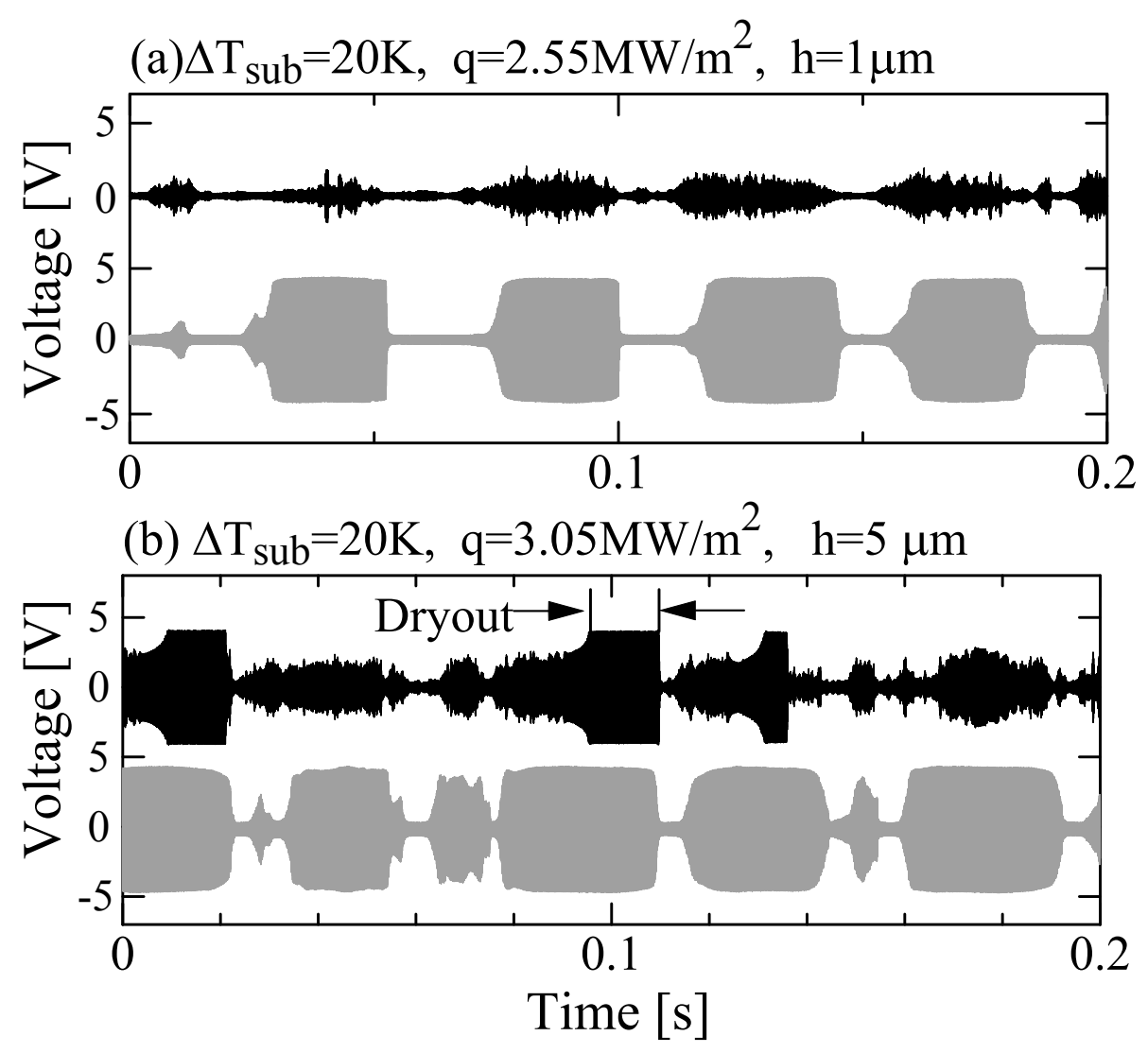

(Upper signal: moving probe. Lower signal: fixed probe.)

Figure 4 Probe signals near the heating surface in the nucleate boiling region and near CHF. 


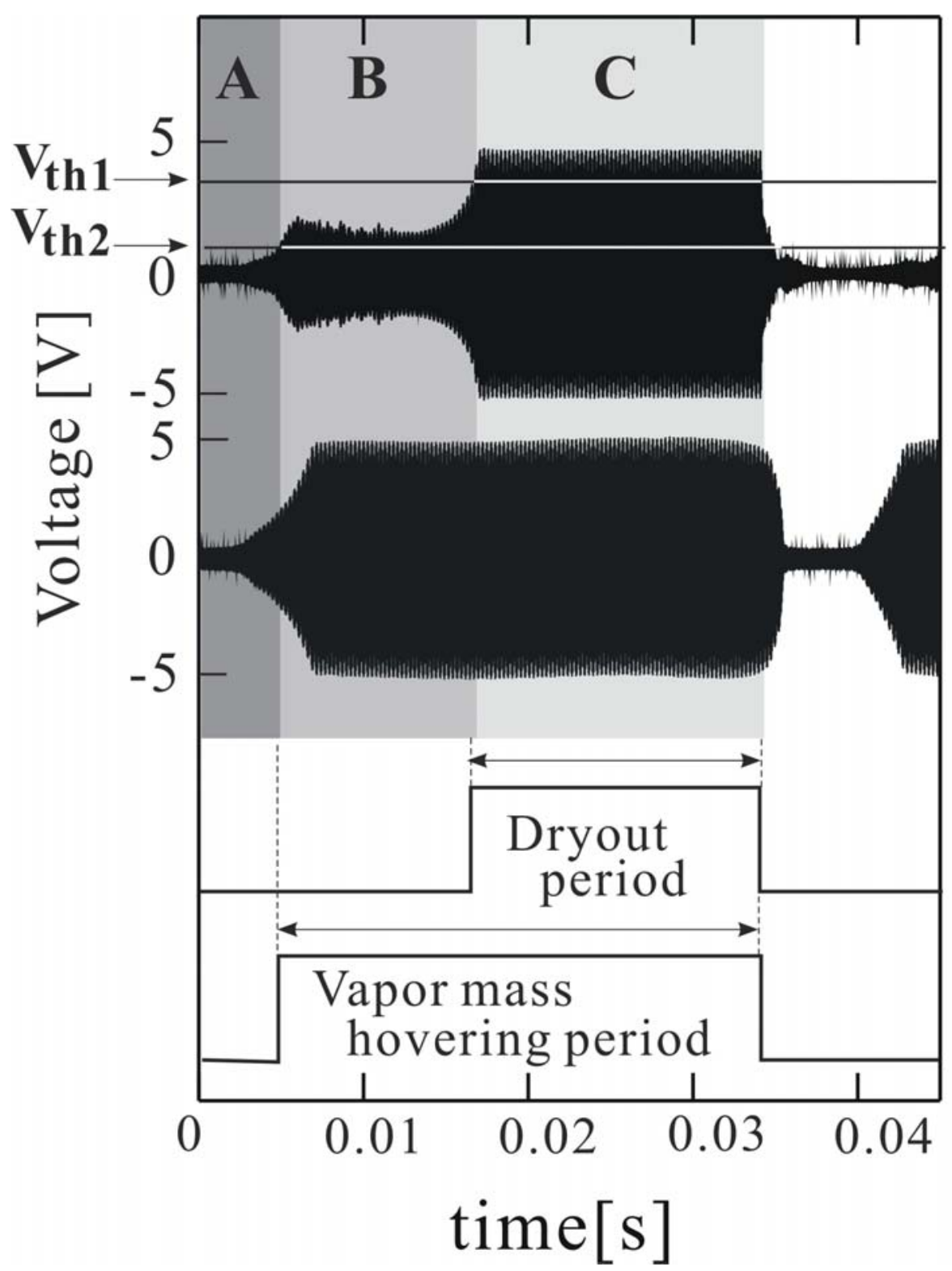

(a)

(b)

(c)

(d)

Figure 5 Three characteristic regions of probe signal detecting surface dryout.

(a) Moving probe signals. (b) Fixed probe signals. (c) Signals digitized with $\mathrm{V}_{\text {th1 }}$.

(d) Signals digitized with $V_{\text {th2 }}$ 


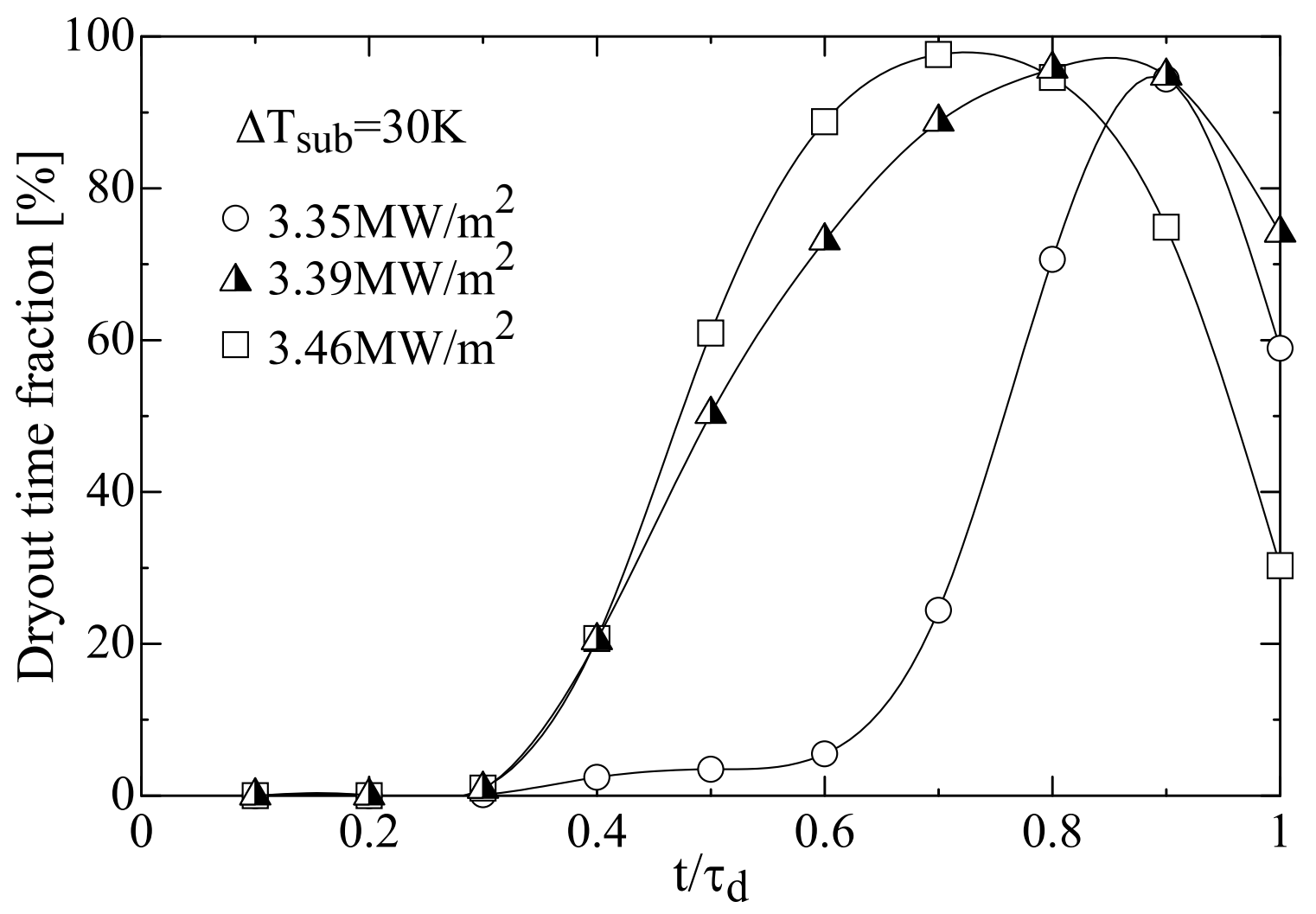

Figure 6 Dryout time fractions during vapor mass hovering. 


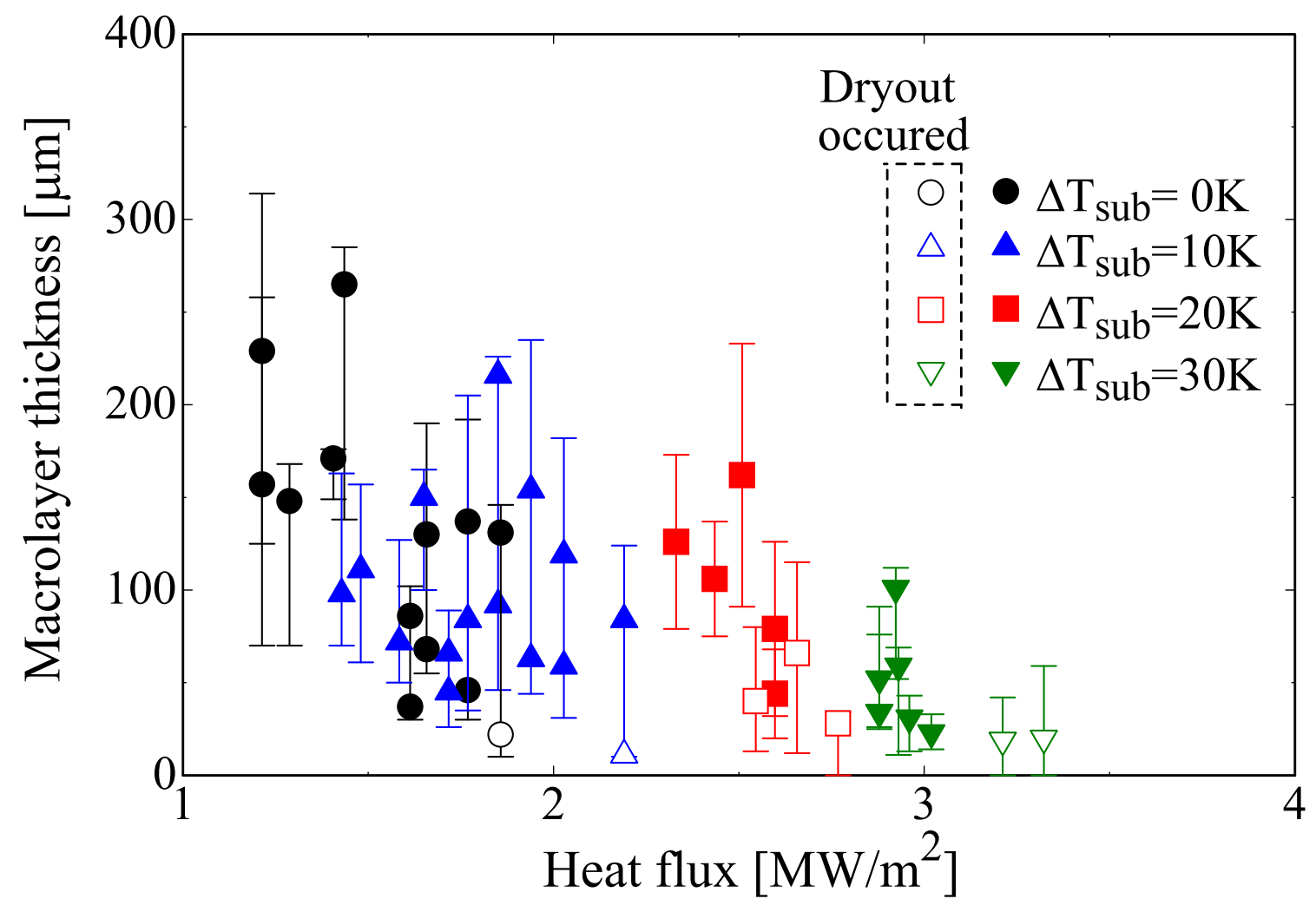

Figure 7 Liquid macrolayer thickness (open symbols indicate surface dryout). 
(a) $2.97 \mathrm{MW} / \mathrm{m}^{2}\left(\Delta \mathrm{T}_{\mathrm{sub}}=20 \mathrm{~K}\right)$

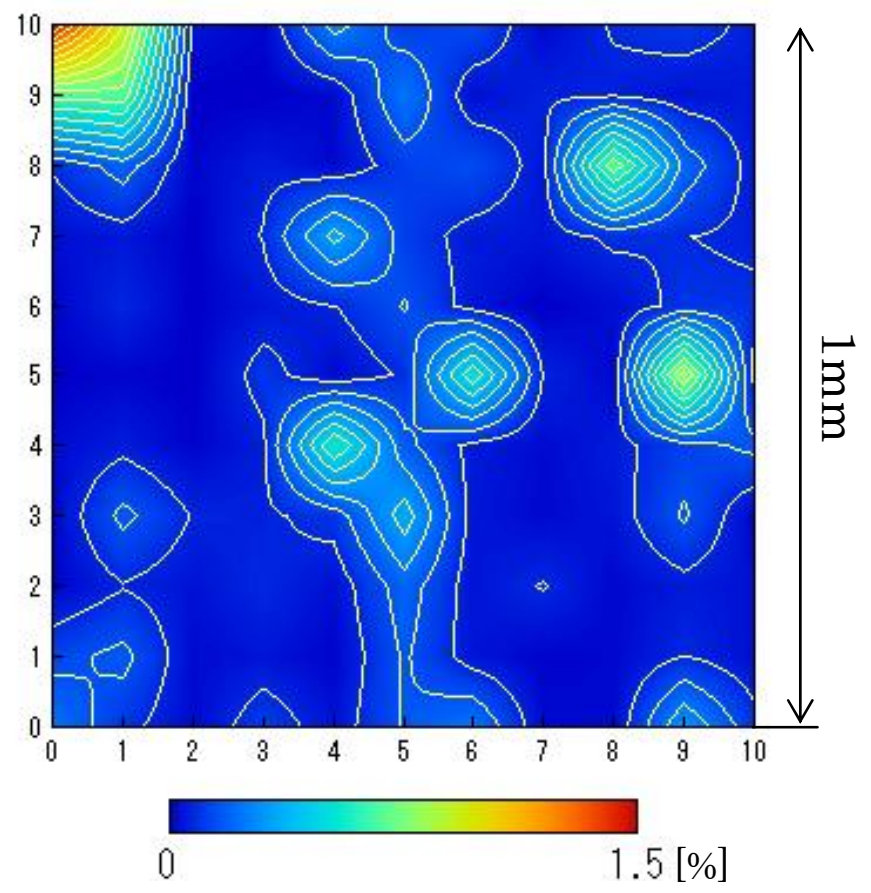

(b) $3.01 \mathrm{MW} / \mathrm{m}^{2}\left(\Delta \mathrm{T}_{\mathrm{sub}}=20 \mathrm{~K}\right)$

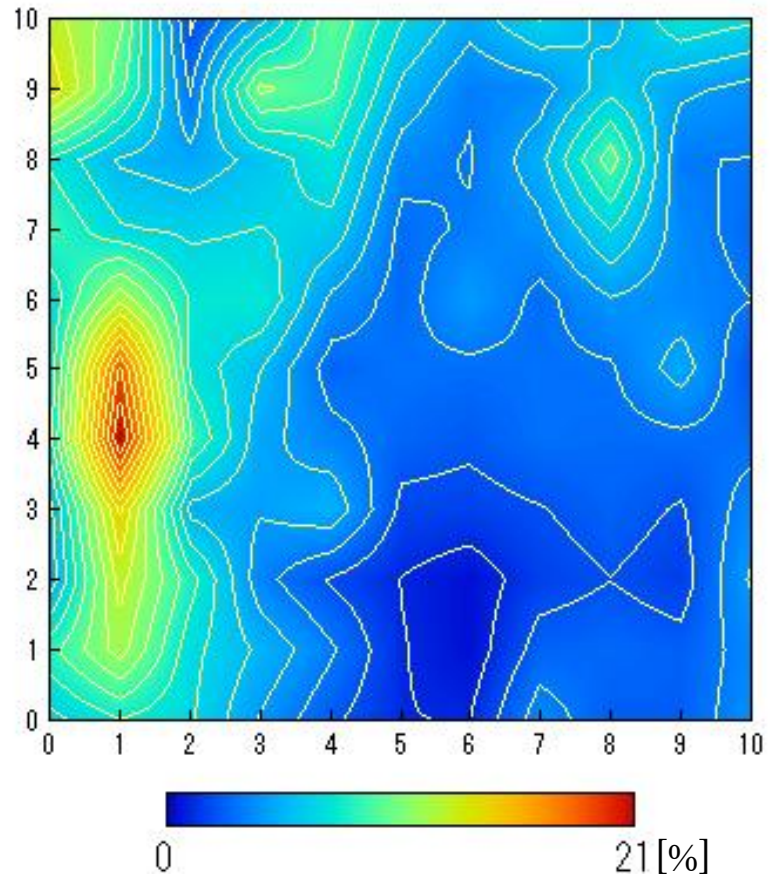

Figure 8 2-D distribution of dryout void fractions. 


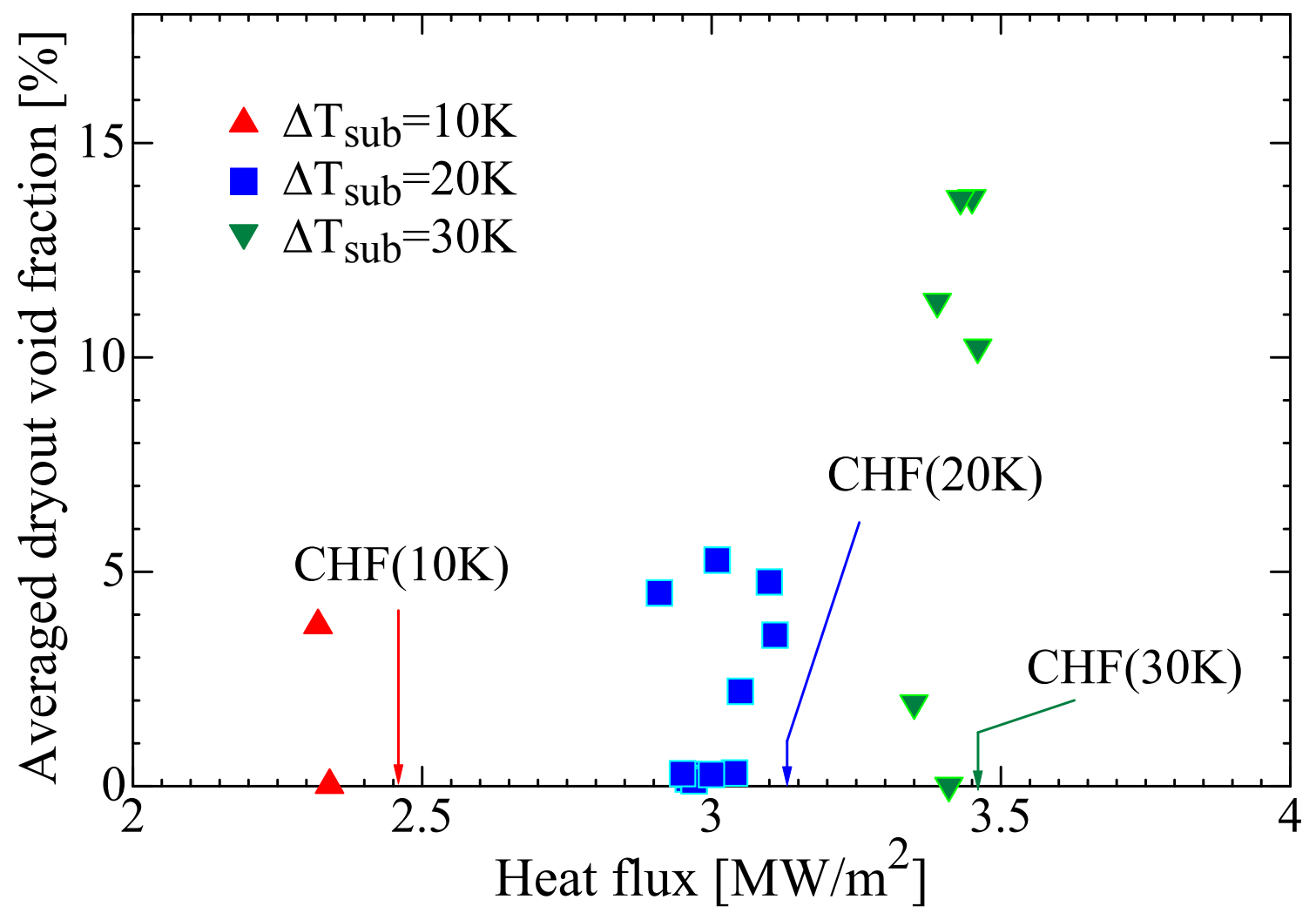

Figure 9 Area-averaged dryout void fractions. 


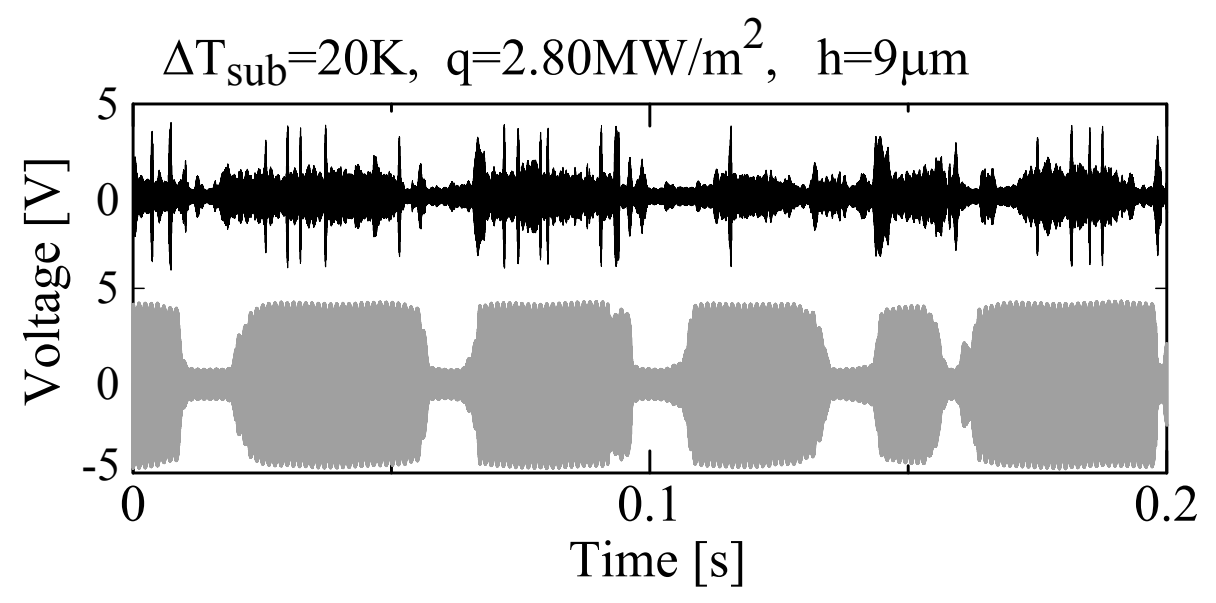

(Upper signal: moving probe. Lower signal: fixed probe. )

Figure 10 Probe signals of primary bubbles. 


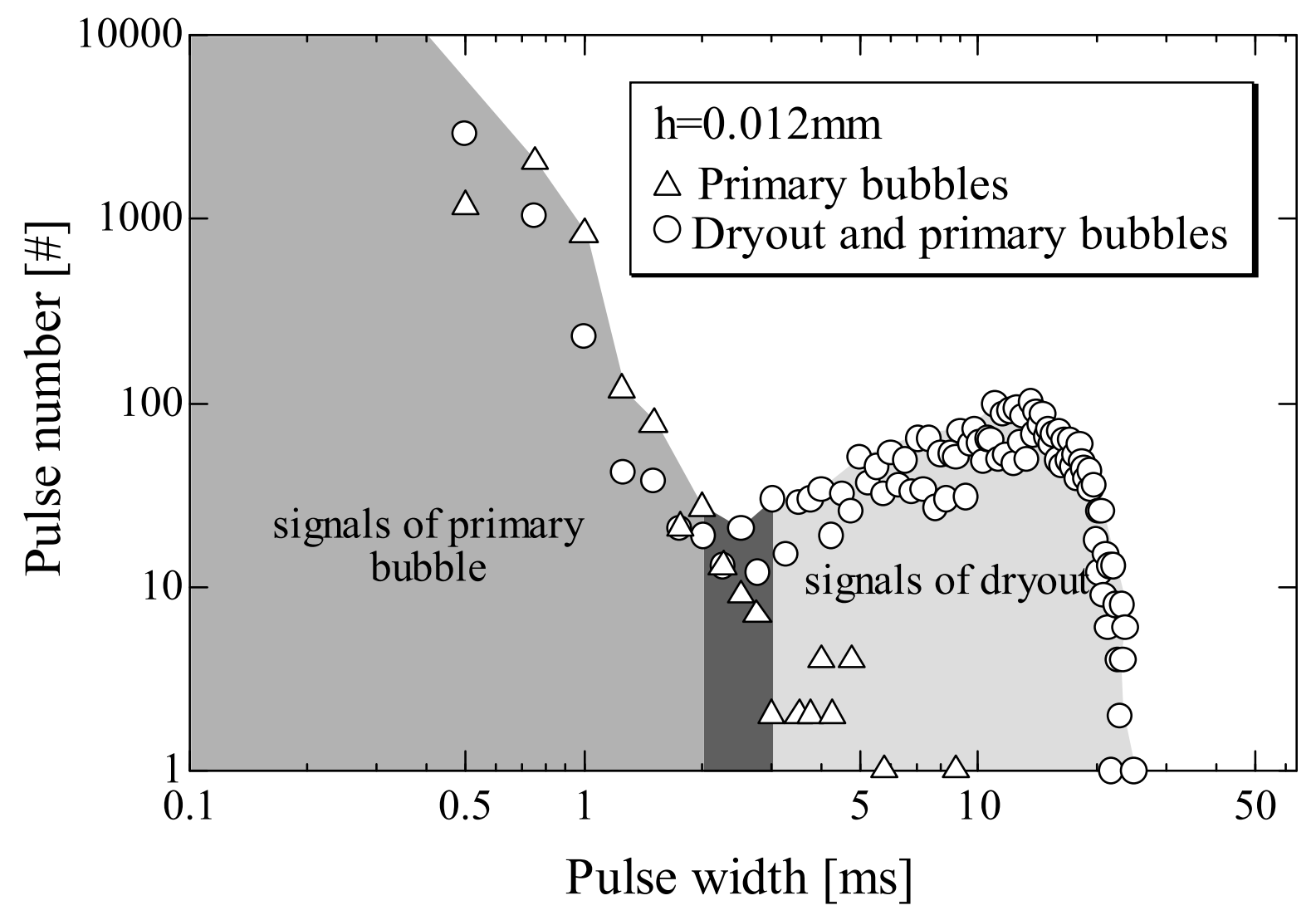

Figure 11 Spectra of pulse widths. 
(a) Dryout frequency

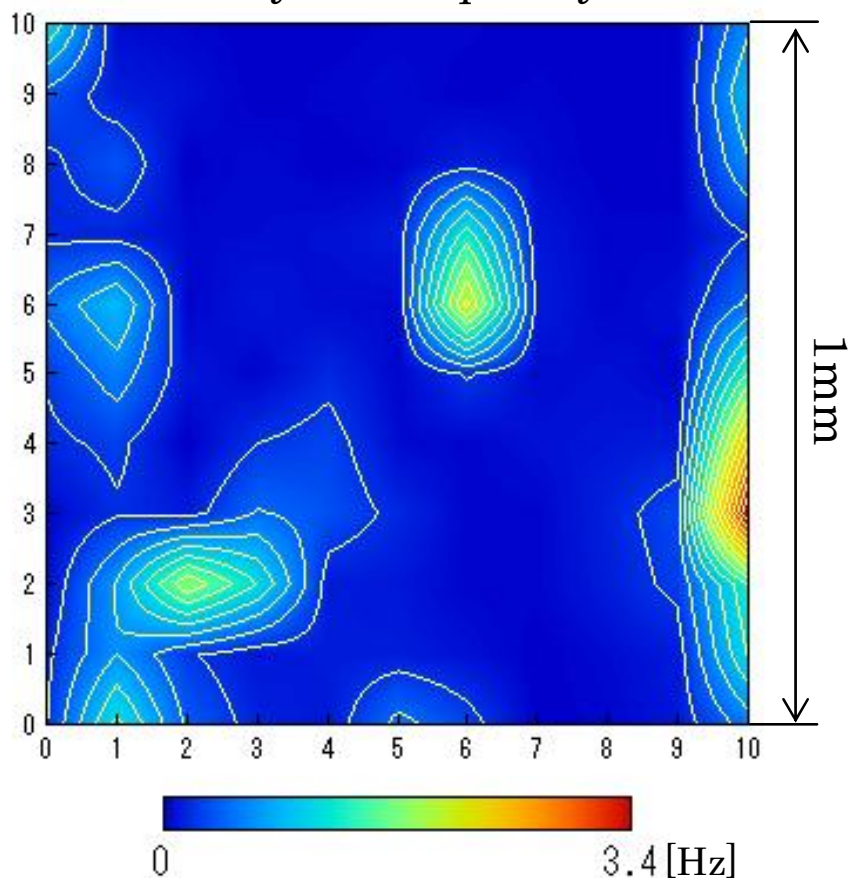

(b) Nucleation frequency

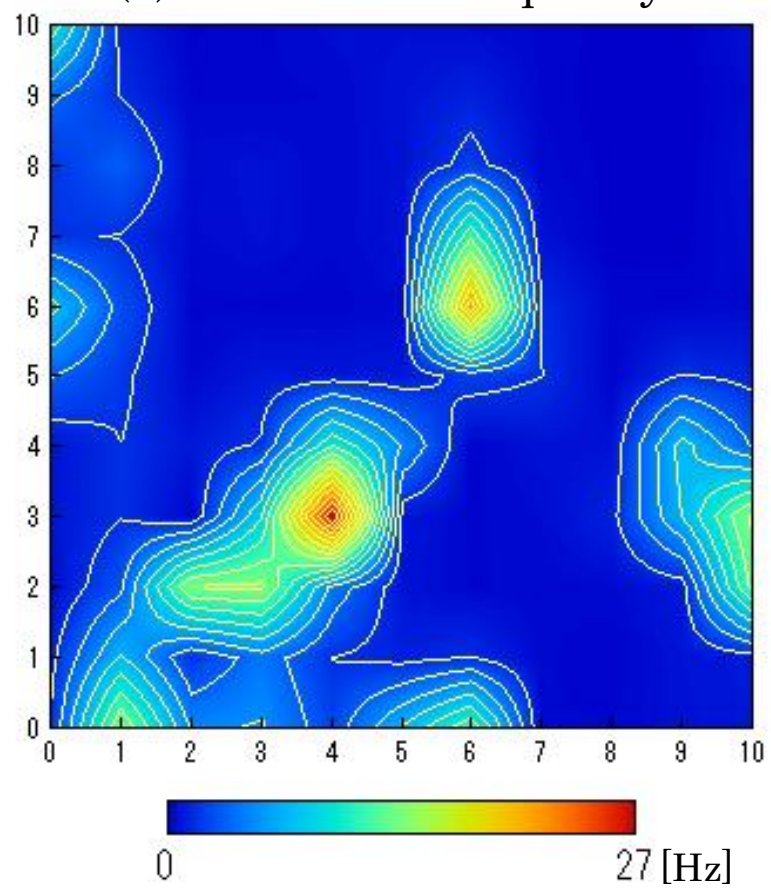

Figure 12 Dryout frequency (a) and nucleation frequency (b).

$$
\left(\Delta \mathrm{T}_{\mathrm{sub}}=20 \mathrm{~K}, \mathrm{q}=2.97 \mathrm{MW} / \mathrm{m}^{2}\right)
$$




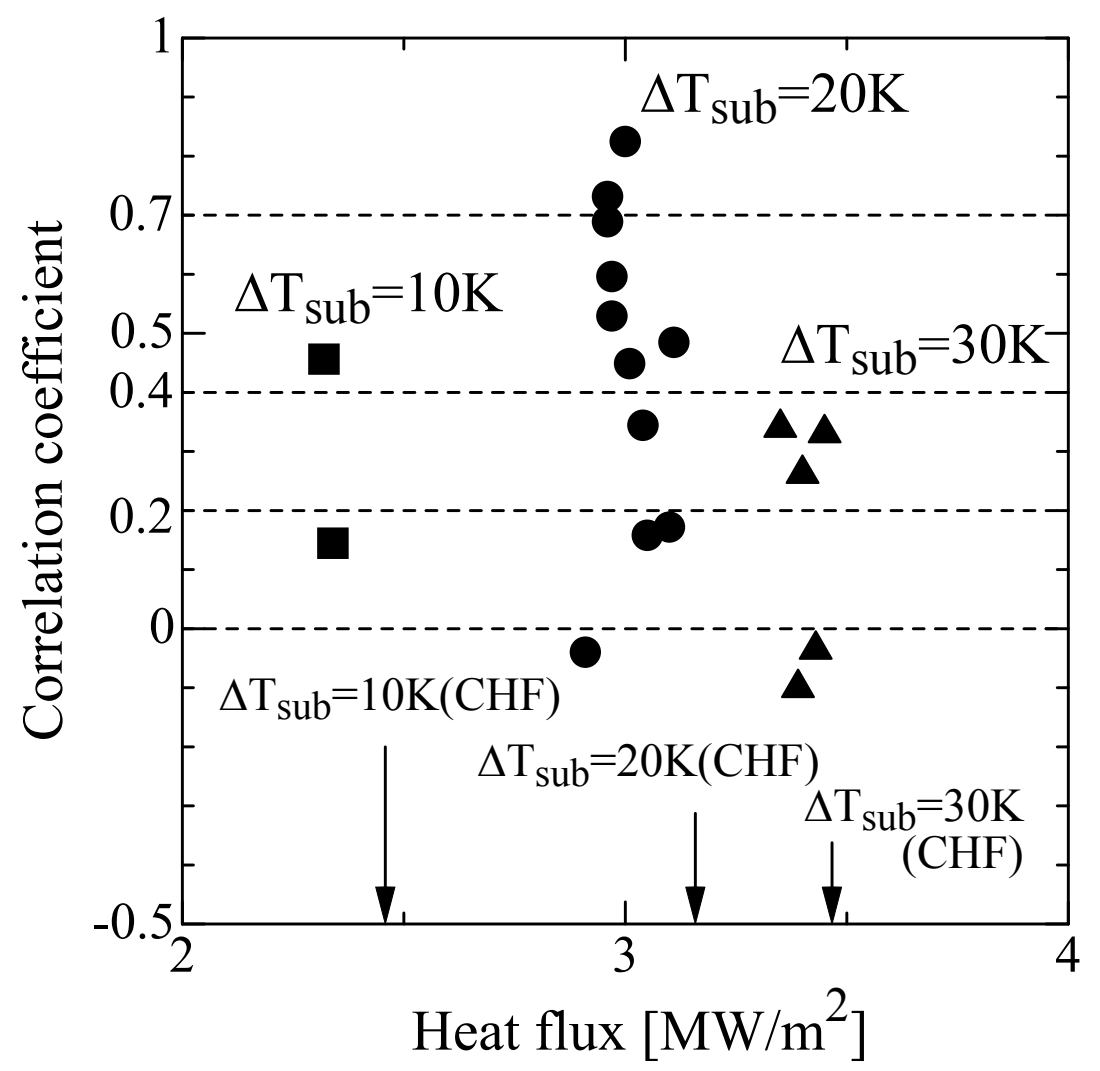

Figure 13 Correlation coefficient between dryout frequency and nucleation frequency. (arrows indicate the heat flux of onset of dryout ). 

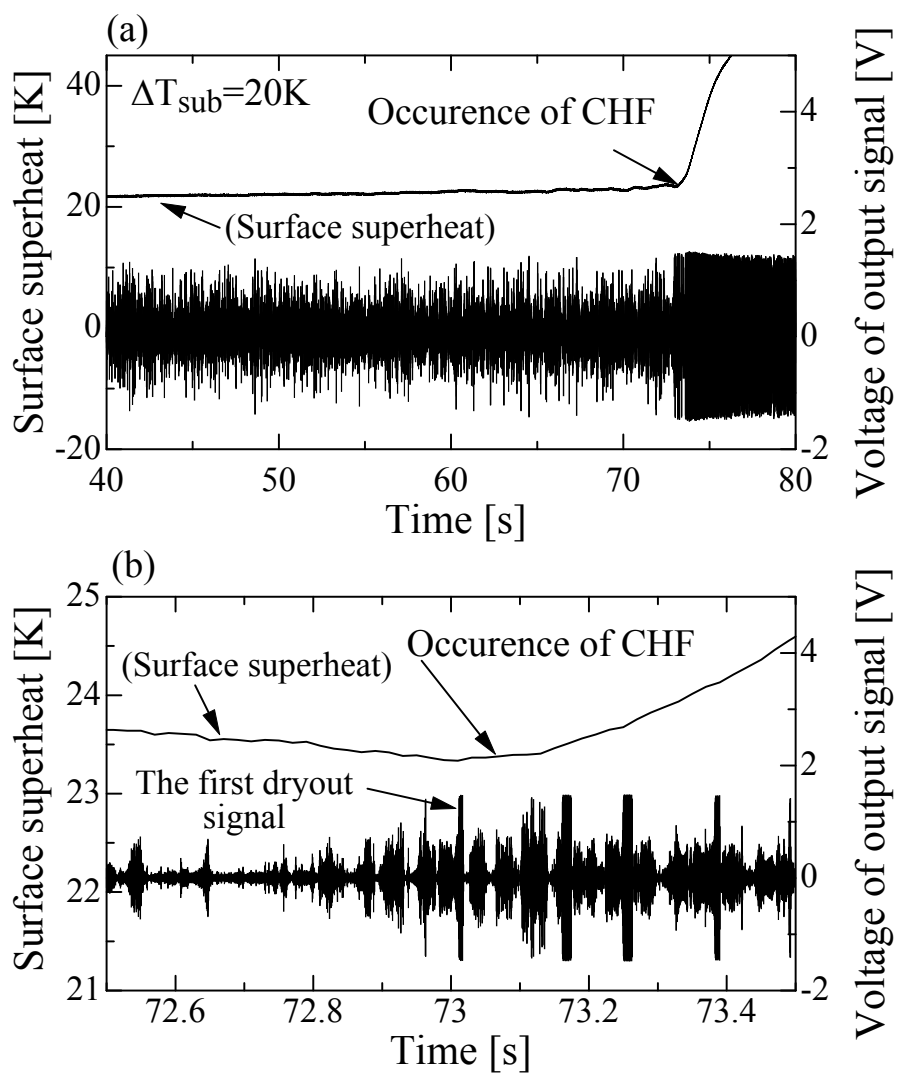

(c)

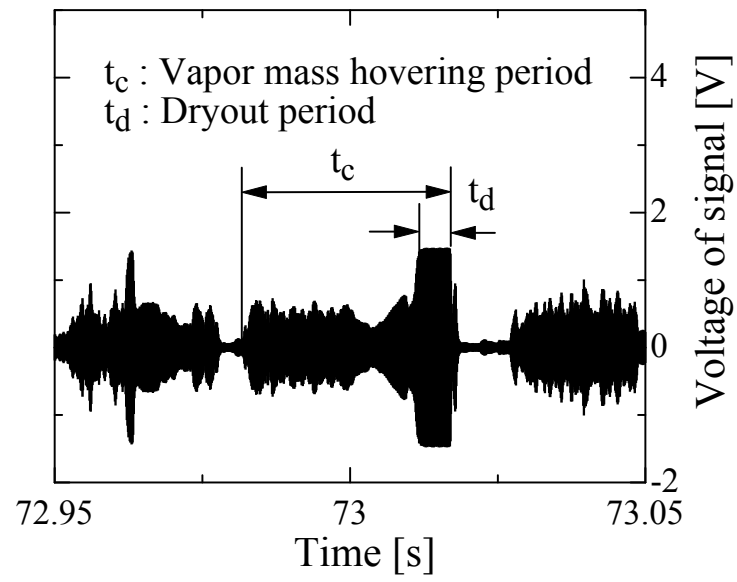

Figure 14 Change in probe signals before and after CHF. 

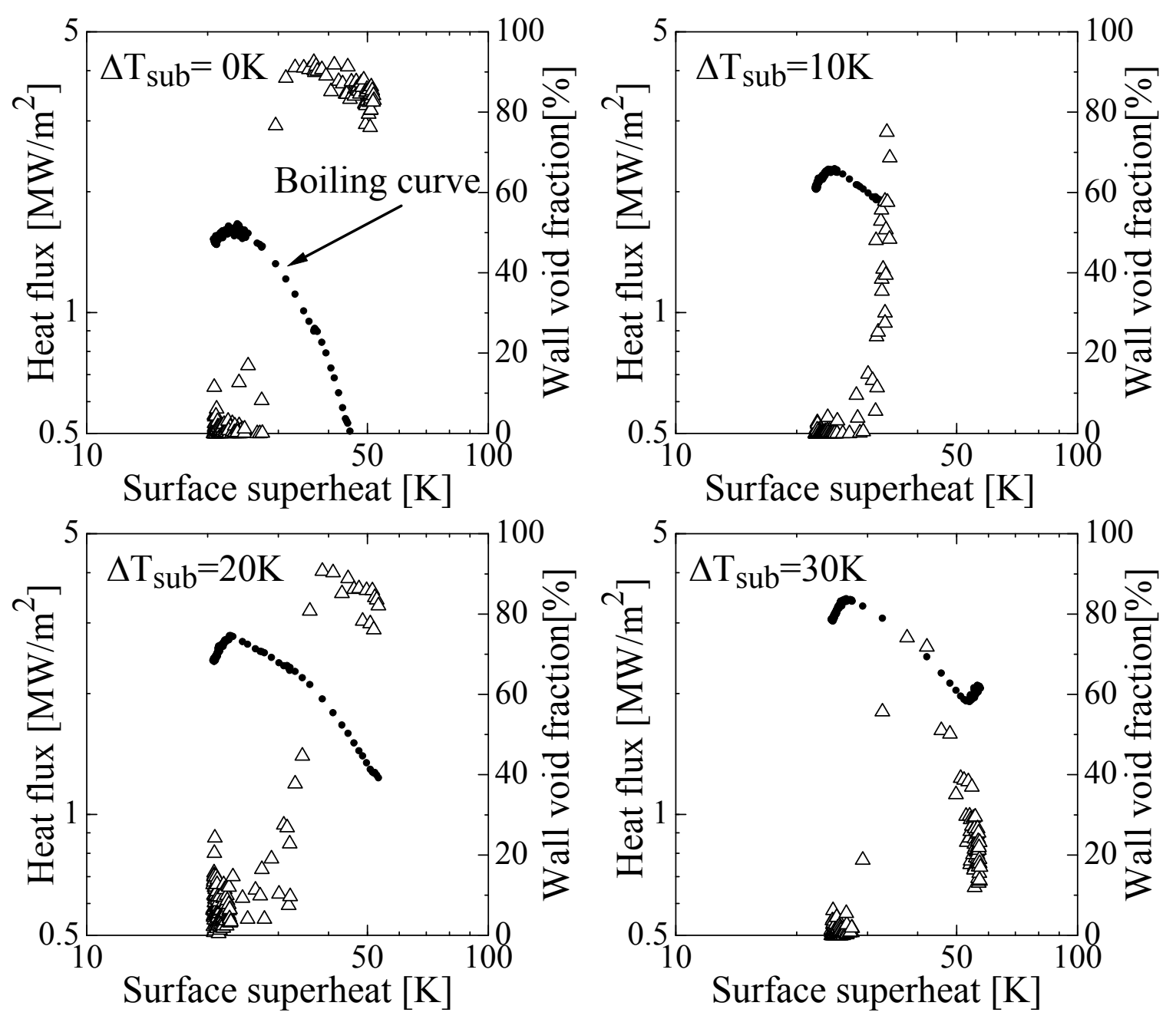

Figure 15 Simultaneously measured boiling curves and wall void fractions. 


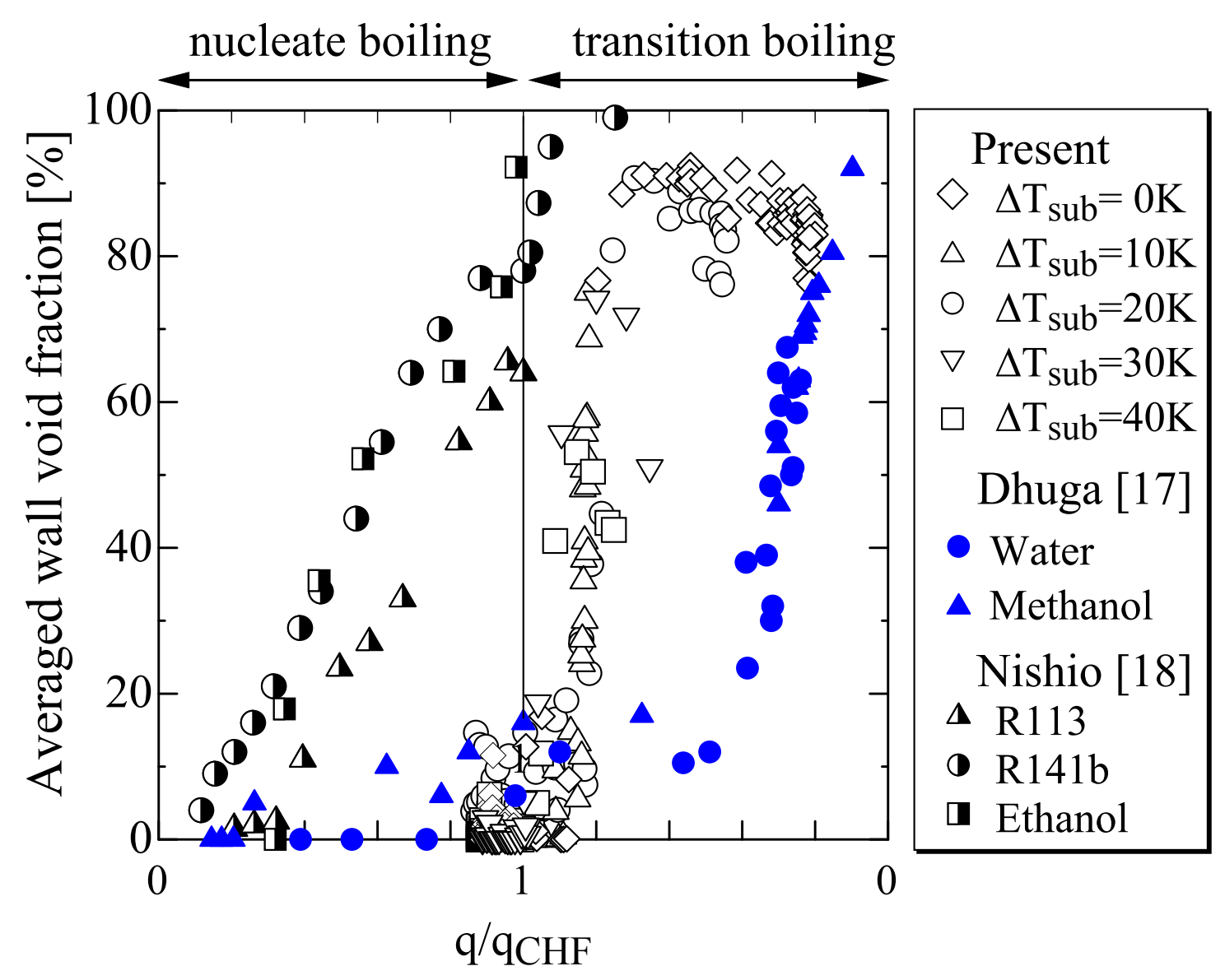

Figure 16 Present and previously reported wall void fractions. 